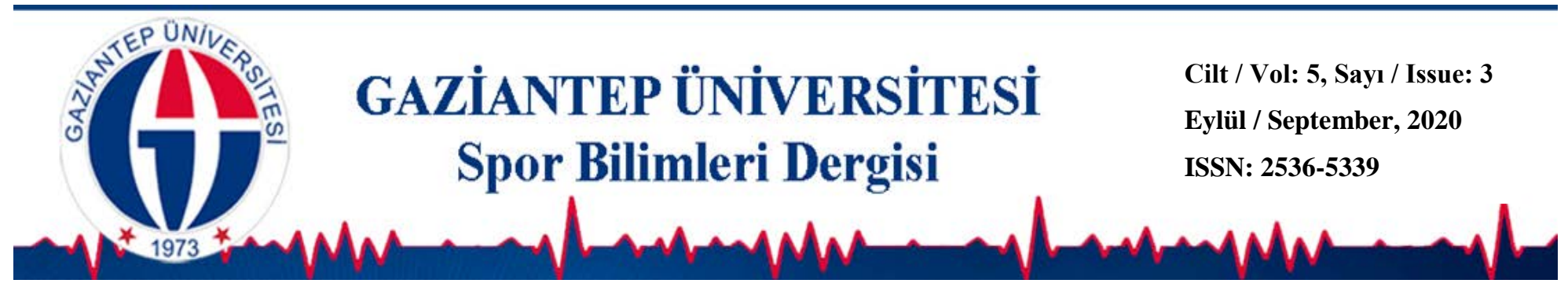

\title{
Basketbolcuların Antrenörden Algıladıkları Demokratik ve Otokratik Davranışın Mevkilere Göre KarşılaştırıIması
}

\author{
Zarife TAŞTAN ${ }^{1 *} \mathbb{D}$ \\ İnci KESILMIŞ $\mathbb{D}$ \\ Turhan TOROS ${ }^{1}$ \\ ${ }^{1}$ Mersin Üniversitesi, Spor Bilimleri Fakültesi, MERSIN \\ ${ }^{2}$ Korkut Ata Üniversitesi, Beden Eğitimi ve Spor Yüksekokulu, OSMANIYE
}

DOI: 10.31680/gaunjss.730591

Orijinal Makale / Original Article

Geliş Tarihi / Received: 01.05.2020～Kabul Tarihi / Accepted: 02.07.2020 Yayın Tarihi / Published: 14.09.2020

Öz

$\mathrm{Bu}$ araştırmanın amacı, basketbolcuların antrenörden algıladıkları demokratik ve otokratik davranışın mevkilere göre karşılaştırılmasıdır. Araştırmanın katılımcılarını 2018-2019 sezonunda, basketbol takımlarında oynayan, 212 erkek basketbolcu oluşturmaktadır. Verilerin toplanmasında Sporda Liderlik Ölçeği (Leadership for Sport ScaleLSS) kullanılmıştır. İstatistiksel analizler için; Betimsel istatistikler, Kolmogorov-Smirnov, Shapiro-Wilks testi, Kruskall Wallis $\mathrm{H}$ testi ve Mann Whitney $\mathrm{U}$ testi kullanılmıştır. Analiz sonuçlarına göre, antrenörün, forvet mevkisinde bulunan basketbolculara otokratik davranış düzeyinin guard mevkisinde bulunan basketbolculardan daha fazla olduğu gözlenmiştir. Guard ve uzun mevkisinde bulunan basketbolcuların antrenörden algıladıkları otokratik davranışlar arasında istatistiksel olarak anlamlı bir fark gözlenmezken, forvet mevkisinde bulunan basketbolcuların antrenörden algıladıkları otokratik davranış düzeylerinin uzun mevkisinde oynayanlardan daha fazla olduğu gözlenmiştir. Antrenörün, guard mevkisinde bulunan basketbolculara forvet mevkisindeki basketbolculardan daha fazla demokratik davrandığı bulunmuştur. Ayrıca antrenörün forvet ve guard mevkisinde bulunan basketbolculara uzun mevkisinde bulunan basketbolculardan daha fazla demokratik davrandığı tespit edilmiştir. Araştırmamız, basketbolcuların oynadığı mevkinin antrenörün demokratik ve otokratik davranış düzeyini artırmada etkili olduğunu göstermektedir.

Anahtar Kelimeler: Basketbol, mevki, liderlik, demokratik, otokratik

\section{Comparison of Democratic and Autocratic Behavior Perceived by the}

\section{Basketball Player from the Coach}

\begin{abstract}
The purpose of this research was to compare the democratic and autocratic behavior perceived by the basketball players from the coach by positions. The participants of the research consisted of 212 male basketball players who played in basketball teams in the 2018-2019 season. Leadership for Sport Scale (LSS) was used to collect the data. For statistical analysis; Descriptive statistics, Kolmogorov Smirnoff- Shapira Wilks test, Kruskall Wallis-H test and Mann Whitney U-test were used. According to the results of the analysis, it has been observed that the level of autocratic behavior of the coach to the basketball players at the striker position is higher than the guard position. While there was no statistically significant difference between the guard and power forward basketball players' autocratic behavior perceived from the coach, the level of autocratic behavior perceived by the basketball players in the striker position was higher than in the power forward position. It was found that the coach was behave more democratic to the guard players than the players at the striker position. Also, It was found that the coach was behave more democratic to the guard and forward players than the players at the power forward. Our research shows that the position played by basketball players is effective in increasing the level of democratic and autocratic behavior of the coach.
\end{abstract}

Keywords: Basketball, position, leadership, democratic, autocratic

\footnotetext{
* Sorumlu Yazar: Zarife TAŞTAN
}

E-mail: zariphe02@gmail.com 


\section{Giriş}

Liderlik, belirlenmiş bir hedefe doğru bir grup insanı bireysel olarak etkileme ve ortak amaca ulaştırmanın davranışsal süreci olarak tanımlanmaktadır (Barrow, 1977; Northouse, 2013). Bütün toplumlarda başarılı liderlerin tipik özelliği, iyi bir takipçi olmayı öğrenerek gelişmeleridir. Liderlerin takipçileriyle olan ilişkilerini incelemeden, liderlik süreçlerinin anlaşılması zor olmaktadır (Clark ve Clark, 1990). Spor kültüründe, spora katııımın büyük kısmında genellikle gençler ve genç yetişkinler yer alırken spor etkinliklerinin organizasyonu ve yönetimi yetişkinler tarafından yürütülmektedir. Bu nedenle, sporda lideri takip etmek bir yetişkin-çocuk ilişkisini içermektedir. Sporda takım liderlerinin "sporcu" kişiliği olması gerektiği varsayımı ön plandadır. Bu varsayımı güçlendirmek için, spor liderlerinin yetenek veya eğitimden bağımsız olarak emekli bir sporcu arasından seçilmesi gibi tipik uygulamalar olmuştur (Williams ve Miller, 1983). Sporda lider olarak görülen antrenörler, kişilik ve liderlik davranışlarında farklılık gösterse de antrenörlerin, sporcuların fiziksel ve psikolojik refahı ve motivasyonları üzerinde büyük bir etkisi olduğuna şüphe yoktur (Chelladurai, 1990; Smith ve Smoll, 1996).

Lider, ortak bir hedefe ulaşmayı amaçlayan grup üyelerinin faaliyetlerini koordine eden sorumluluk pozisyonunda olan kişidir (Yukl, 1989). Liderler; etkili olmak, aynı zamanda vizyon sahibi olmak, risk almaya istekli ve değişime adapte olabilmek için birçok niteliğe sahip olmalıdır. Lider ayrıca örgütün değerlerini, amaçlarını ve kültürünü örneklendirmelidir (Van Seters ve Field, 1990). Takım oyunlarında takımın her üyesinin kişisel potansiyeli farklıdır. Liderin işi takım oyuncularının kişisel potansiyellerine ulaşmalarında yardımcı olmaktır. Liderler, bir takımı belirli bir hedefe veya sonuca yönlendirirken, talimat verebilmeli, beceri geliştirmeye rehberlik edebilmeli ve performans geribildirimi sunabilmelidirler. Bu nedenle, lider olan antrenörlerin; sporcularının ve takımlarının başarısında, sporcuların benlik saygısı (Barnett, Smoll ve Smith, 1992), beceri öğrenimi (Chelladurai, 1984) gibi faktörleri etkileyen bir rol oynaması şaşırtıcı olmayacaktır. Antrenör, sporcu ve antrenman ortamı arasındaki karmaşık örüntüyü açıklamak için yapılan çalışmalar, antrenör davranışlarının sporcunun gelişimini doğrudan etkilediğini göstermektedir (Chelladurai, 1984; Smoll ve Smith, 1984). Antrenörsporcu ilişkisi ne kadar olumlu, uyumlu ve güçlü olursa, sporcular genellikle ilgili sporlarında daha faydalı bir deneyim yaşamaktadırlar (Poczwardowski, Henschen ve 
Barott, 2002). Antrenörlerin liderlik davranışları ve sporcu arasındaki uyum ile birlikte sporcuların doyum düzeyleri ve takım performansı artmaktadır (Chelladurai, 2007). Kısacası sporcunun hedefleri, kişiliği ve inançları antrenörünkilerle tutarlıysa, etkileşim muhtemelen her iki taraf için de tatmin edici olacaktır. Bu durum olumlu kişiler arası bir atmosfer ile sonuçlanacaktır (Kenow ve Williams, 1999). Bunun için antrenörlerin eğitim hedeflerini ve liderlik tarzlarını rekabetçi ortama göre ayarlamaları ve sorumlu oldukları kişilere özgü yaşam döngüsü ihtiyaçlarını karşılamaları gerekebilmektedir (Jambor ve Zhang 1997; Hersey ve Blanchard,1982). Antrenörler için zor olan, takım başarısına elverişli bir liderlik tarzı bulmaktır. Antrenörlerin liderlik tarzları üzerine yapılan önemli araştırmalara rağmen, "Sporda hangi liderlik tarzı en iyi takım performansını elde etmek için daha etkilidir?" sorusunun cevabını bulmak hala zordur. Bu liderlik özelliklerini ölçmek için Chelladurai ve Saleh (1980) Sporda Liderlik Ölçeğini (Leadership for Sport ScaleLSS) geliştirmişlerdir. LSS'nin, 5 alt boyutu (Eğitim ve Öğretim Davranışı, Demokratik Davranış, Otokratik Davranış, Sosyal Destek Davranışı, Pozitif Geribildirim Davranışı) bulunmaktadır. Ölçeğin, eğitim ve öğretim alt boyutunda; sert ve yorucu antrenman vurgulanarak, sporculara sporun becerileri, teknikleri ve taktiklerini öğretmek ve sporcuların faaliyetlerini yapılandırarak koordine etmek gibi sporcuların performansını artırmaya yönelik liderlik davranışı ölçülmektedir. Demokratik Davranış alt boyutunda; sporcuların grup hedefleri, uygulama yöntemleri, oyun taktikleri ve stratejileri ile ilgili kararlara daha fazla katıımını sağlayan liderlik davranışı ölçülmektedir. Otokratik Davranış alt boyutunda; oyunculardan bağımsız karar almayı içeren ve kişisel otoriteyi vurgulayan liderlik davranışı ölçülmektedir. Sosyal Destek alt boyutunda; sporcuların bireysel refahı, pozitif grup atmosferi ve sporcularla sıcak kişilerarası ilişkiler kurmak için çabalayan liderlik davranışı ölçülmektedir. Pozitif Geribildirim alt boyutunda ise; bir sporcunun iyi performansını ödüllendirerek güçlendiren liderlik davranışı (Chelladurai, 1990) ölçülmektedir. LSS kullanan araştırmaların çoğu, antrenörlerin spordaki liderlik davranışlarına odaklanmıştır.

Takım oyunlarında farklı pozisyonlarda bulunan oyuncuların mevkilerinin gerektirdiği yetenek ve becerileri birbirinden farklıdır. Bu yüzden antrenörlerin, sporcuların bulundukları mevkilere göre sporculardan talepleri farklılaşmaktadır. Bir mevkide etkili olan bir davranış diğer mevkide etkili olmayabilir. Basketbol gibi takım başarısının önemli olduğu branşlarda, oyuncuların tamamının oyun planının 
yürütülmesinde etkin rolü vardır (Campion, Medsker, ve Higgs 1993). Ancak mevkinin gerektirdiği özellikler doğrultusunda antrenörler belirli bir zamanda sadece tek bir takım oyuncusuyla da çalışmalar yürütmektedir. Takımın tüm üyelerinin nasıl oynadıkları ve belirli bir zamanda belirli bir mevkide konumlandırıma olasılıkları son derece önemlidir. Oyuncunun bulunduğu mevki ile birlikte diğer takım oyuncuları ile paylaşıı̆ı toplam deneyim burada kritik bir değişkendir. Takım oyuncuları birlikte çalışmak için ne kadar fazla zaman harcarlarsa, birbirlerinin yeteneklerini anlamak ve takdir etmek, bireysel oyunlarını buna göre senkronize etmek için gereken bireysel bilişsel şemaları geliştirme olasılıkları da bu sayede artmaktadır. Başka bir deyişle, basketbol sahası, bir takımın zihinlerinde ortaklaşa destekledikleri bilgi birikimlerinin değer kazandığı önemli bir ortamdır (Berman, Down, ve Hill, 2002). Bu bilgi birikimlerin antrenör ve sporcular arasında paylaşılması da önemlidir.

$\mathrm{Bu}$ bilgiler ışığında bu araştırmanın amacı; basketbolcuların antrenörden algıladıkları demokratik ve otokratik davranışın mevkilere göre karşılaştırılmasıdır.

\section{Yöntem}

\section{Evren ve Örneklem}

Araştırmanın katıımcılarını 2018-2019 sezonunda, basketbol takımlarında oynayan, gönüllü olarak araştırmaya katılan profesyonel 212 erkek basketbol oyuncusu oluşturmaktadır.

\section{Verilerin Toplanması}

Araştırma verileri; araştırmaya gönüllü katııım sağlayan sporculara, Sporda Liderlik Ölçeği uygulanarak toplanmıştır.

\section{Veri Toplama Araçları}

Sporda Liderlik Ölçeği: Chelladurai ve Saleh $(1978,1980)$ tarafından geliştirilen Sporda Liderlik Ölçeğinin (Leadership for Sport Scale-LSS) üç formu bulunmaktadır. Ölçek; (a) sporcuların antrenörleri için tercih ettikleri lider davranışları, (b) antrenörlerin kendi lider davranışları ya da ideal lider davranışı, (c) sporcuların antrenörleriyle ilgili algıladıkları gerçek lider davranışlarını ölçmek için geliştirilmiştir (Chelladurai ve Saleh, 1980). Bu araştırmada ölçeğin (c) formu kullanılmıştır. Ölçek 40 maddeden oluşan beşli likert tipi (her zaman, sıklıkla, ara sıra, nadiren, hiçbir 
zaman) bir ölçektir. Sporda Liderlik Ölçeği, beş alt boyuta (Eğitim ve Öğretim davranışı, Demokratik Davranış, Otokratik Davranış, Sosyal Destek Davranışı, Pozitif Geribildirim Davranışı) ayrılmıştır. Ölçeğin Türk sporcuları için uyarlanması Toros ve Tiryaki (2006) tarafından yapılmıştır. Ölçekteki her bir alt boyut, bir liderlik davranışını ifade etmektedir. Çalışmada, demokratik ve otokratik davranış alt boyutlar ele alınarak antrenör davranışları incelenmiştir.

\section{Verilerin analizi}

Çalışmada verileri analiz etmek için SPSS 20.00 programı kullanılmıştır. Araştırmadan elde edilen veriler, bilgisayar ortamına aktarıldıktan sonra Betimsel İstatistikler ve Kolmogorov Smirnov- Shapiro Wilk testinden yararlanarak dağılımın normalliği test edilmiştir. Veriler normal dağılım varsayımını karşılamadığı için Tek Yönlü Varyans Analizinin (ANOVA) non-parametrik karşılığı olan, Kruskal Wallis $\mathrm{H}$ testi ve ikili karşılaştırmalarda Mann Whitney U-testi kullanılmıştır. Anlamlıık düzeyi $\mathrm{p}<0.05$ olarak alınmıştır.

\section{Bulgular}

Analiz sonuçları, basketbolcuların bulunduğu mevkilere göre antrenörden algıladıkları otokratik davranışların anlamlı bir şekilde farklılaştığını göstermektedir, $\chi^{2}(\mathrm{sd}=2, \mathrm{n}=212)=19.75, \mathrm{p}<0.05$. Bu bulgu basketbolcuların bulunduğu mevkinin antrenörün otokratik davranışları üzerinde farklı etkilere sahip olduğunu gösterir. Mevkilerin sıra ortalamaları dikkate alındığında, antrenörden algılanan otokratik davranışın forvet mevkisinde bulunan basketbolcularda daha yüksek olduğu, bunu guard ve uzun mevkisinde bulunan basketbolcuların takip ettiği görülmektedir (Tablo 1) Basketbolcuların bulunduğu mevkilere göre antrenörden algıladıkları demokratik davranışlar da istatistiksel olarak anlamlı bir şekilde farklılaşmaktadır, $\chi^{2} \quad(s d=2$, $n=212)=33.78, p<0.05$. Bu bulgu basketbolcuların bulunduğu mevkinin antrenörün demokratik davranışları üzerinde farklı etkilere sahip olduğunu gösterir. Mevkilerin sıra ortalamaları dikkate alındığında, antrenörün demokratik davranışının guard mevkisinde bulunan basketbolcularda daha fazla olduğu, bunu forvet ve uzun mevkisinde bulunan basketbolcuların takip ettiği görülmektedir (Tablo 1). 
Taştan, Z., Kesilmiş, İ. ve Toros, T. (2020). Basketbolcuların Antrenörden Algıladıkları Demokratik ve Otokratik Davranışın Mevkilere Göre Karşılaştırılması. Gaziantep Üniversitesi Spor Bilimleri Dergisi, 5(3), 219230.

Tablo 1. Liderlik Davranışı Kruskall Wallis H Testi Sonuçları

\begin{tabular}{|c|c|c|c|c|c|c|}
\hline Liderlik Davranışı & Mevki & $\mathbf{N}$ & Sira Ort. & SD & $\chi^{2}$ & p \\
\hline \multirow{3}{*}{ Otokratik Davranış } & Guard & 71 & 95,63 & \multirow{3}{*}{2} & \multirow{3}{*}{19,756} & \multirow{3}{*}{$0,000 *$} \\
\hline & Forvet & 81 & 128,62 & & & \\
\hline & Uzun & 60 & 89,50 & & & \\
\hline \multirow{3}{*}{ Demokratik Davranış } & Guard & 71 & 136,29 & \multirow{3}{*}{2} & \multirow{3}{*}{33,785} & \multirow{3}{*}{$0,000^{*}$} \\
\hline & Forvet & 81 & 101,88 & & & \\
\hline & Uzun & 60 & 77,49 & & & \\
\hline
\end{tabular}

Mevkiler arasında gözlenen anlamlı farkın, hangi mevkiler arasındaki anlamlı farklara bağlı olarak ortaya çıktığını belirmek için Mann Whitney U testi uygulanarak farkın kaynağı incelenmiştir (Tablo 2).

Tablo 2. Liderlik Davranışı Mann Whitney U Testi Sonuçları

\begin{tabular}{|c|c|c|c|c|c|c|}
\hline Liderlik Davranışı & Mevki & $\mathbf{N}$ & Sira Ort & Sira Top & $\mathbf{U}$ & $\mathbf{p}$ \\
\hline \multirow{6}{*}{ Otokratik Davranış } & Guard & 71 & 62.63 & 4446.50 & \multirow[t]{2}{*}{1890.50} & \multirow{2}{*}{$0.000^{\star}$} \\
\hline & Forvet & 81 & 88.66 & 7181.50 & & \\
\hline & Guard & 71 & 69.00 & 4899.00 & \multirow{2}{*}{1917,00} & \multirow{2}{*}{0.299} \\
\hline & Uzun & 60 & 62.45 & 3747,00 & & \\
\hline & Forvet & 81 & 80.96 & 6558.00 & \multirow{2}{*}{1623.00} & \multirow{2}{*}{$0.000^{*}$} \\
\hline & Uzun & 60 & 57.55 & 3453.00 & & \\
\hline \multirow{6}{*}{ Demokratik Davranış } & \multirow{2}{*}{$\begin{array}{l}\text { Guard } \\
\text { Forvet }\end{array}$} & 71 & 89.94 & 6386.00 & \multirow[t]{2}{*}{1921.00} & \multirow{2}{*}{$0.000^{*}$} \\
\hline & & 81 & 64.72 & 5242.00 & & \\
\hline & Guard & 71 & 82.35 & 5846.50 & \multirow{2}{*}{969.50} & \multirow{2}{*}{$0.000^{*}$} \\
\hline & Uzun & 60 & 46.66 & 2799.50 & & \\
\hline & Forvet & 81 & 78.16 & 6331.00 & \multirow[t]{2}{*}{1850.00} & \multirow{2}{*}{$0.008^{*}$} \\
\hline & Uzun & 60 & 61.33 & 3680.00 & & \\
\hline
\end{tabular}

${ }^{\star} \mathrm{p}<.05$

Guard ve forvet mevkisinde bulunan basketbolcuların antrenörden algıladıkları otokratik davranış puanlarının Mann Whitney $U$ testi sonuçları Tablo 2'de verilmiştir. Buna göre antrenörün guard ve forvet mevkisinde bulunan basketbolculara otokratik davranışları arasında anlamlı bir fark olduğu bulunmuştur, $U=1890.5, p<0.05$. Sıra ortalamaları dikkate alındığında, forvet mevkisinde bulunan basketbolculara antrenörün daha fazla otokratik davranış sergilediği görülmektedir. Bu bulgu, mevkinin antrenörün otokratik davranış düzeyini artırmada etkili olduğunu göstermektedir. Tablo 2 ye göre guard ve uzun mevkisinde bulunan basketbolcuların antrenörden algıladıkları otokratik davranışlar arasında anlamlı bir fark olmadığı bulunmuştur, $U=1917.00, \quad p>0.05$. Forvet ve uzun mevkisinde bulunan basketbolcuların antrenörden algıladıkları otokratik davranış puanlarının Mann Whitney $U$ testi sonuçlarına göre, forvet ve uzun mevkisinde bulunan basketbolcuların algıladıkları otokratik davranışlar arasında anlamlı bir fark olduğu 
bulunmuştur, $U=1623.00, p<0.05$. Sıra ortalamaları dikkate alındığında, antrenörün forvet mevkisinde bulunan basketbolculara daha fazla otokratik davranış sergilediği görülmektedir. Bu bulgu, mevkinin antrenörün otokratik davranış düzeyini artırmada etkili olduğunu göstermektedir.

Forvet ve guard mevkisinde bulunan basketbolcuların demokratik davranış puanlarının Mann Whitney $U$ testi sonuçları Tablo 2'de verilmiştir. Buna göre, basketbolcuların antrenörden algıladıkları demokratik davranışlar arasında anlamlı bir fark olduğu bulunmuştur, $U=1921.00, p<0.05$. Sıra ortalamaları dikkate alındığında, guard mevkisinde bulunan basketbolcuların antrenörden algıladıkları demokratik davranış düzeylerinin daha fazla olduğu görülmektedir. Forvet ve uzun mevkisinde bulunan basketbolcuların antrenörden algıladıkları demokratik davranış puanlarının Mann Whitney $U$ testi sonuçlarına göre, forvet ve uzun mevkisinde bulunan basketbolcuların demokratik davranışları arasında anlamlı bir fark olduğu bulunmuştur, $U=1850.50, p<0.05$. Sıra ortalamaları dikkate alındığında, antrenörün forvet mevkisinde bulunan basketbolculara daha fazla demokratik davranış sergilediği görülmektedir. Guard ve uzun mevkisinde bulunan basketbolcuların demokratik davranış puanlarının Mann Whitney $U$ testi sonuçları göre, guard ve uzun mevkisinde bulunan basketbolcuların antrenörden algıladıkları demokratik davranışları arasında anlamlı bir fark olduğu bulunmuştur, $U=969.50, p<0.05$. Sıra ortalamaları dikkate alındığında, guard mevkisinde bulunan basketbolcuların algıladıkları demokratik davranış düzeylerinin daha fazla olduğu görülmektedir. Bu bulgular, mevkinin antrenörün sergilediği demokratik davranış düzeyini artırmada etkili olduğunu göstermektedir.

\section{Tartışma ve Sonuç}

Takım sporlarında oyuncular arası etkileşim yoğundur ve sporcular takımın lideri olarak gördükleri antrenörün davranışlarından etkilenmektedirler. Basketbol branşı da oyuncular arası etkileşimin çok yoğun olduğu ve maç sırasında antrenör ile sporcuların sürekli iletişim halinde olduğu branşlardan biridir. Basketbolcular görevlerine göre mevkilere ayrılırlar. Farklı mevkilerde oynayan sporcuların farklı psikolojik özelliklere sahip olması gerektiği düşünülmektedir (Najah ve Rejeb, 2015). Buna göre farklı mevkilerde oynayan basketbolcuların antrenörlerini algılama biçimlerinin farklı olabileceği düşüncesi desteklenmektedir. Araştırmamızda 
Taştan, Z., Kesilmiş, İ. ve Toros, T. (2020). Basketbolcuların Antrenörden Algıladıkları Demokratik ve Otokratik Davranışın Mevkilere Göre Karşılaştırılması. Gaziantep Üniversitesi Spor Bilimleri Dergisi, 5(3), 219230.

antrenörün sergilediği demokratik ve otokratik davranışların basketbolcuların mevkilerine göre anlamlı şekilde farklılaştığı gözlenmiştir. Antrenörün, forvet mevkisinde bulunan basketbolculara otokratik davranış düzeyinin guard mevkisinde bulunan basketbolculardan daha fazla olduğu görülmektedir. Guard ve uzun mevkisinde bulunan basketbolcuların antrenörden algıladıkları otokratik davranışlar arasında istatistiksel olarak anlamlı bir fark gözlenmezken, forvet mevkisinde bulunan basketbolcuların antrenörden algıladıkları otokratik davranış düzeylerinin uzun mevkisinde oynayanlardan daha fazla olduğu görülmektedir. Antrenörün, guard mevkisinde bulunan basketbolculara forvet mevkisindeki basketbolculardan daha fazla demokratik davrandığı görülmektedir. Ayrıca antrenörün forvet ve guard mevkisinde bulunan basketbolculara uzun mevkisinde bulunan basketbolculardan daha fazla demokratik davrandığı görülmektedir. Bu bulgular, basketbolcuların oynadığı mevkinin antrenörün demokratik ve otokratik davranış düzeyini artırmada etkili olduğunu göstermektedir.

Araştırmamı ile benzer şekilde; Grobbelaar ve Eloff (2011), hücum ve savunma bölgelerinde oynayan Netball ve basketbol oyuncularının başarı motivasyonu seviyelerinin merkezde oynayan oyunculardan daha yüksek olduğu sonucuna ulaşmışlardır. Yine araştırmamız ile benzer şekilde, Türksoy ve Şarkıcı (2003) futbolcuların oynadığı mevkiye göre tercih ettikleri lider davranışının eğitim ve antrenman boyutunda farklııık tespit etmişler, defans oyuncularının kalecilere göre antrenörlerinden daha fazla eğitim ve antrenman beklentisinde olduklarını sonucunu elde etmişlerdir. Taştan, Kesilmiş, ve Toros (2020), futbolcuların bulunduğu mevkilere göre algılanan liderlik davranışlarında, otokratik davranışın savunma mevkisinde bulunanlarda daha yüksek olduğu, bunu orta ve hücum mevkisinin takip ettiği sonucuna ulaşmışlardır. Demokratik davranışın ise orta mevkisinde bulunanlarda daha yüksek olduğu, bunu savunma ve hücum mevkisinin takip ettiğini bildirmişlerdir. Literatürde araştırmamızdan farklı sonuçlar elde eden çalışmalar da mevcuttur. Çakıoğlu (2003) futbolcularda pozisyona göre tercih edilen liderlik, algılanan liderlik ve liderlikten memnuniyet konusunda hücum, savunma ve orta saha oyuncuları arasında istatistiksel olarak fark gözlememiştir. Çik (2019) Türkiye Basketbol Gençler Liginde görev alan antrenörlerin yeterlikleriyle, sporcular tarafından algılanan antrenör davranışları arasındaki ilişkinin incelenmesi amacı ile yaptığı araştırmada mevkiye göre sporcular tarafından algılanan antrenör davranışlarında anlamlı bir fark 
gözlememiştir. Bensiz (2016) amatör futbolcuların algılarına göre antrenörlerin liderlik özelliklerinin incelenmesi amacıyla yaptığı araştırmada, amatör futbolcuların liderlik davranışları puan ortalamalarının sporcuların mevkilerine göre incelendiğinde istatistiksel olarak anlamlı bir farklılık olmadığı sonucunu elde etmiştir.

Antrenörlerin demokratik davranışı grup hedefleriyle, çalışma yöntemleriyle, oyun taktikleri ve stratejileriyle ilgili olarak sporcuların daha büyük katılımına izin vermeleri şeklindedir. Araştırmamızda guard oyuncuları en yüksek demokratik davranış puanını elde etmişlerdir. Guard oyuncusu, basketbolda oyun kurucudur, asist yapmak ve diğer takım oyuncularına basket imkânı sağlamak için pozisyon üretmeye ve oyunu kurmaya çalışırlar. Guard oyuncuları, pozisyonlarının gerektirdiği sorumluluğun bir sonucu olarak takımı doğru yönlendirmeler ile yönetirler. Demokratik liderler karar verirken ve görevlerin paylaşımı sırasında sporculardan en iyi performansı alabilmek adına grup üyelerine danışmaktadırlar. Araştırma sonuçlarımıza göre guard oyuncularının demokratik davranış puanlarının yüksek olması oynadıkları mevkinin gerektirdiği özelliklerden kaynaklanabilir. Guard oyuncusu demokratik bir lider ile çalıştı̆ıında oyun kurucu olarak üstlendiği görevi daha başarıı bir şekilde sergileyebilecektir. Otokratik lider davranışında antrenör sporculardan bağımsız olarak kararlar vermektedir ve oyuncular antrenörün kararlarını yerine getirmektedir. Araştırmamızda forvet oyuncuları hem guard hem de uzun oyuncularından otokratik davranış puanlarında daha yüksek skor elde etmiştir. Forvet oyuncularının mevkileri gereği görevleri çok fazladır. Takımın skor yükünü paylaşmada rol oyuncusudur. Bu nedenle otokratik lider davranışı puanlarının diğer mevkilerde oynayan sporculardan yüksek olduğu söylenebilir.

Bireysel antrenman ve sporcuların görev aldıkları mevkilere göre antrenmanın önemi giderek artmakta ve önemi antrenörler tarafından fark edildikçe sporculara bireysel çalışma imkanının tanınması giderek artmaktadır. Bu nedenle sporcuların mevkilerinin fizyolojik ve psikolojik getirilerinin araştırıması önem kazanmaktadır. Araştırmamız basketbol branşı ile sınırlıdır. Liderlik davranışı ve mevkiler ile ilgili farklı takım sporlarında uygulanacak araştırmalar ile daha kapsamlı bilgiye ulaşılabileceği önerilmektedir.

\section{Kaynaklar}


Barnett, N. P., Smoll, F. L. and Smith, R. E. (1992). Effects of enhancing coach-athlet relation ships on youth sport attrition. The Sport Psychologist, 6, 111-127.

Barrow, J. C. (1977). The variables of leadership: A review and conceptual framework. Academy of Management Review, 2(2), 231-251.

Bensiz, A. (2016). Amatör futbolcuların algılarına göre antrenörlerin liderlik özelliklerinin incelenmesi. (Yüksek Lisans tezi). Bartın Üniversitesi, Eğitim Bilimleri Enstitüsü, Bartın.

Berman, S.L., Down, J. and Hill, C.W L. (2002). Tacit knowledge as a source of Competitive advantage in the National Basketball Association. Academy of Management Journal, 45, 1, 18.

Campion, M. A., Medsker, G. J. and Higgs, A. C. (1993). Relations between work group characteristics and effectiveness: Implications for designing effective work groups. Personnel Psychology, 46.

Chelladurai, P. (1984). Discrepancy between preferences and perceptions of leadership behavior and satisfaction of athletes in varying sports. Journal of Sport Psychology, 6, 27-41.

Chelladurai, P. (1990). Leadership in sports: A review. International Journal of Sport Psychology, 21, 328-354.

Chelladurai, P. (2007). Leadership in sports. In g. Tenenbaum and R. C. Eklund (Eds.). Handbook of Sport Psychology (3rd. ed., pp. 111-135). New Jersey, NJ: John Wiley and Sons, Inc.

Chelladurai, P. and Saleh, S.D. (1978). Preferred leadership in sports. Canadian. Journal of Applied Sport Sciences, Vol.3, 85-92.

Chelladurai, P. and Saleh, S.D. (1980). Dimensions of leader behavior in sports: Development of a leadership scale. Journal of Sport Psychology, Vol.2, 34-45.

Clark, K. E. and Clark, M. B. (1990). What is a leader? What is leadership? In K. E. Clarkand M. B. Clark (Eds.) Measures of Leadership pp. 30-34). Greensboro, NC: Center for Creative Leadership.

Çakıoğlu, A. (2003). Futbolda liderlik ve sporcu tatmini: tercih edilen ve gerçek liderlik davranışı arasındaki uyum ve sporcu pozisyonu açısından değerlendirilmesi. (Yüksek Lisans tezi), Orta Doğu Teknik Üniversitesi, Sosyal Bilimler Enstitüsü, Ankara. 
Çik, B. (2019). Sporcular tarafından algılanan antrenör davranışlarının antrenörlerin yeterliğiyle ilişkisinin incelenmesi. (Yüksek Lisans Tezi). Marmara Üniversitesi, İstanbul.

Grobbelaar, H. W., and Eloff, M. (2011). Psychological skills of provincial netball players in different playing positions. South African Journal for Research in Sport, Physical Education and Recreation, 33 (2): 45-58.

Hersey, P. and Blanchard, K. (1982). Management of organization behavior: Utilizing human resources (4th ed.). Upper Saddle River, NJ: Prentice Hall, Inc.,

Jambor, E. A and Zhang, J. J. (1997). Investigating leadership, gender, and coaching level using the revised leadership of sport scale. Journal Sport Behavior, 20: 313-321.

Kenow, L. J and Williams, J. M. (1999). Coach-athlete compatibility and athletes' perception of coaching behaviors. Journal Sport Behavior, 22: 251-259.

Najah, A., Rejeb, R. B. (2015). The psychological profile of youth male soccer players in different playing positions. Advances in Physical Education , 5:161-169.

Northouse, P. G. (2013). Leadership: Theory and practice (6th Ed.). Thous and Oaks, CA: Sage.

Poczwardowski, A, Henschen, K. P. and Barott, J. E. (2002). The athlete and coach: Their relation ship and its meaning: Results of an interpretive study. International Journal of Sports Psychol 33: 116-140.

Smith, R.E. and Smoll, F.L. (1996). The coach as a focus of research and intervention in youth sports. In F. L. Smoll and R. E. Smith (Eds.), Children and youth in sport. A biopsychosocial perspective (pp. 125-141). Dubuque, IA: Brown and Benchmark.

Smoll, F. L. and Smith, R. E. (1984). Leadership research in youth sports. In J. M. Silva III and R. S. Weinberg (Eds.), Psychological foundations of sport (pp. 371386). Champaign, IL: Human Kinetics.

Taştan, Z., Kesilmiş, M. M., Toros, T. (2020). Futbolcularda mevkilere göre algılanan liderlik davranışı. Sağlık-Toplum-Bilim Akademik Araştırmalar Kitap-5. Paradigma Akademi, İstanbul. ISBN: 978-605-7691-76-7.

Toros, T. ve Tiryaki, Ş. (2006). Sporda liderlik ölçeği'nin futbolcuların antrenör davranışlarını algılaması versiyonunun geçerlik ve güvenirlik çalışması. 9.Uluslararası Spor Bilimleri Kongresi, 3-5 Kasım 2006, Muğla, Türkiye. 
Taştan, Z., Kesilmiş, İ. ve Toros, T. (2020). Basketbolcuların Antrenörden Algıladıkları Demokratik ve Otokratik Davranışın Mevkilere Göre Karşılaştırılması. Gaziantep Üniversitesi Spor Bilimleri Dergisi, 5(3), 219230.

Türksoy, A. ve Şarkıcı, T. (2003). 12-14 yaş futbolcuların antrenörlerinden algıladıkları ve tercih ettikleri lider davranışları ile ilgili sporcu tatmini. Istanbul Üniversitesi Spor Bilimleri Dergisi. 11(3):(ÖS), 200-203.

Van Seters, D., Field, R. (1990). The evolution of leadership theory. Journal of Organizational Change Management, 3, 29-45.

Williams, J. M., and Miller, D. M. (1983). Inter collegiate athletic administration: Preparation patterns. Research Quarterly, 54(4), 398-406.

Yukl, G. (1989). Managerial leadership: A review of theory and research. Journal of Management, 15(2), 251-289. 